\title{
The role of public health in addressing child maltreatment in Canada
}

\author{
S. M. Jack, RN, PhD (1)
}

\begin{abstract}
Child maltreatment is a significant health and social issue given its prevalence across the general population and the significant short- and long-term outcomes associated with maltreatment in childhood. There is a need for a comprehensive, collaborative and multisectoral approach for identification, prevention and intervention of this complex issue. Within this multisectoral collaboration, it is essential for public health in Canada to define its role in addressing and preventing child maltreatment. This commentary summarizes how public health can address the issue of child maltreatment in Canada by specifically: 1) measuring the magnitude of maltreatment through public health surveillance systems such as the Canadian Incidence Study of Reported Child Abuse and Neglect; 2) identifying modifiable risk factors; 3 ) identifying and evaluating communitybased interventions to prevent violence; and 4) implementing evidence-based primary prevention strategies.
\end{abstract}

Keywords: primary prevention, public health, child abuse, intervention, nurse home visitation, Nurse-Family Partnership, child maltreatment, surveillance

\section{Introduction}

Child maltreatment involves the harm, or the potential for harm, to a child or youth by an adult who they trust or depend upon. ${ }^{1}$ This harm may occur through either an act of commission (e.g. physical, sexual or emotional abuse) or an act of omission (e.g. physical, emotional or medical neglect, failure to supervise or exposure to violence). ${ }^{1}$ Maltreatment in childhood is associated with short- and long-term physical, social, emotional and cognitive impairment that can last a lifetime.,2,3 Exposure to maltreatment in childhood is common: approximately one-third of adult Canadians report histories of physical or sexual abuse or both during childhood. ${ }^{4}$

Child maltreatment can be difficult to identify, as there is a lack of consensus across jurisdictions and sectors (health care, law, education, justice) about which "acts" constitute abuse. As a health and social issue, child maltreatment is difficult to prevent, as there are risk indicators at individual, family and societal levels to address. It is also difficult to intervene or treat child maltreatment as different sectors have distinct roles and responsibilities for responding to maltreatment. Given this complexity, there is a need for a comprehensive, collaborative and multisectoral approach for identification, prevention and intervention.

While all professionals working in the different sectors have a legal responsibility to report suspected or observed maltreatment to child welfare services, the different sectors have unique roles in responding to the issue (Table 1). It is essential that public health in Canada defines its role in addressing child maltreatment within such a multisectoral collaboration as it is the sector that connects the biological and individual determinants of impairment with the social, economic and political determinants that influence population health. ${ }^{5}$

\section{Public health approach to child maltreatment}

This commentary summarizes how a public health approach to child maltreatment can be applied in Canada by specifically: 1) measuring the magnitude of maltreatment through public health surveillance systems; 2) identifying modifiable risk factors; 3) identifying and evaluating community-based interventions to prevent violence; and 4) implementing evidencebased primary prevention strategies.

\section{Public health approach to addressing problems}

The public health approach ${ }^{5-7}$ to addressing problems has four distinct steps: 1) measurement of the scope and magnitude of the problem using surveillance and epidemiological methods; 2) identification of the causes and correlates associated with the problem, including any risk or protective indicators that may be modified through intervention or prevention programs; 3) development, implementation and subsequent evaluation of interventions; and 4) implementation of those evidence-based interventions that have been determined to affect relevant and clinically important outcomes. 


\section{Measurement of child maltreatment in Canada}

At the federal level, the Public Health Agency of Canada (PHAC) defines and measures the incidence of and risk indicators associated with child maltreatment, and the service outcomes of child maltreatment investigations. An emerging priority is to ensure that these data are accessible to provincial/territorial and regional public health decision makers responsible for defining public health issues and implementing primary prevention programs. In public health, the scope and magnitude of an issue is measured using epidemiological and surveillance data; PHAC coordinates the Canadian Incidence Study of Reported Child Abuse and Neglect (CIS), a national public health surveillance system conducted every five years to capture data on five categories of maltreatment in children from birth to 15 years of age: neglect, emotional abuse, exposure to domes tic violence, sexual and physical abuse. In the fall of 2003, child protection workers collected data for the CIS-2003 from a representative sample of 63 child welfare service areas across Canada that followed a total of 14200 child maltreatment investigations. In Quebec, data were extracted from an administrative information system; in all other provinces and territories, child protection workers completed a standardized assessment form. ${ }^{8}$ Data collected included the characteristics of the investigated child(ren), details of the maltreatment investigation, level of substantiation, child health outcomes, service dispositions, and family and household characteristics.

However, Pless argues that public health surveillance systems are often focussed on the diligent collection and analysis of data and that these findings are rarely shared in a timely fashion with those decision makers motivated to and reponsible for taking action and implementing prevention programs. ${ }^{9}$ He concludes by stating that "the ideal solution is to make surveillance serve the goal of prevention." Although the CIS is coordinated through PHAC, the CIS findings are primarily communicated to the general public or audiences of child welfare decision makers ${ }^{10}$ mandated to identify maltreated children and to deliver secondary prevention programs to reduce rates of recurrence and impairment associated with abuse and neglect. ${ }^{11}$ To support the planning, implementation and evaluation of primary prevention programs, the CIS surveillance data should be disseminated to decision makers and public health researchers in those provincial and local-level public health agencies responsible for implementing such programs. Increased access to child maltreatment surveillance data would give targeted public health decision makers: 1) increased awareness of the CIS findings; 2) statistics to position child maltreatment as a public health priority and thus prioritize resource allocation towards primary prevention programs; 3) information on child maltreatment trends; 4) data on risk indicators that can be modified through public health interventions; 5) augmented understanding of referral patterns to child welfare by public health professionals; 6) opportunites to identify research priorities related to maltreatment; and 7) the ability to identify populations for targeted primary prevention programs.

At present, the CIS provides the best available snapshot on the incidence of child maltreatment in Canada; however, there are several limitations to this national surveillance system. First, the utility of the results are limited in that the findings provide national level data and are not valid at the local level due to sampling procedures. ${ }^{8}$ Within each cycle, however, provinces and territories can provide resources for oversampling to obtain jurisdictional estimates of the magnitude of child maltreatment. Second, there has been no formal evaluation of the CIS surveillance system, so its effectiveness at collecting, analyzing and disseminating the data is unknown. Third, to plan culturally relevant prevention programs, it is essential to collect accurate data, particularly from the groups determined to be at risk. The CIS has not yet obtained a representative sample of First Nations agencies, although the number of participating agencies is increasing with each subsequent CIS cycle-a promising finding.

Fourth, the most significant limitation is that the surveillance findings are determined by a single source of data-child welfare agency reports. Thus, while the CIS is a rich source of information on child welfare investigations, because it does not include information on police investigations of maltreatment or unreported cases of abuse or neglect, the true burden of maltreatment in the population is underestimated. To garner a comprehensive understanding of the health of Canadian children, what is required is a network of public health surveillance systems linked to other health information surveys and sources characterized by common data elements, mechanisms for timely data collection and distribution, and ease of access to the data. ${ }^{12}$ In the United States, the Centers for Disease Control and Prevention is developing alternate systems to collect information from hospital and emergency departments on fatal and non-fatal child maltreatment and on victims of violence to develop a National Violent Death Reporting System. ${ }^{13}$ These data sources will be used together with findings from the National Child Abuse and Neglect Data System and the US National Incidence Study of Child Abuse and Neglect, which includes sentinel surveys of community professionals working with children and families outside of the child welfare system, ${ }^{14}$ to more accurately measure child maltreatment. In Australia, there is a system that links data from different health and social service administrative datasets for all children to enhance the quality of child protection data. ${ }^{15}$ In Canada, PHAC, given its establishment and coordination of the CIS and other health surveillance systems, is optimally positioned to collaborate in the development of an integrated surveillance system that would be informed by more than just reports investigated by child welfare.

\section{Identification of determinants of child maltreatment}

Multiple individual, household and community risk indicators are associated with physical abuse, sexual abuse and neglect. ${ }^{16}$ The CIS provides information on risk factors for public health researchers and decision makers to conduct secondary analyses to answer relevant questions around child maltreatment and to organize into conceptual frameworks as foundations for developing child maltreatment 
prevention strategies; 5 these risk factors include child characteristics (e.g. age, gender, ethnic background), caregiver and child functioning (e.g. exposure to intimate partner violence, substance abuse, mental health issues, parental history of childhood maltreatment) and household characteristics (e.g. structure, family size, income, employment). While not intended for collecting community level data, the CIS also provides some insight into social determinants of maltreatment such as housing problems, low employment rates and poverty.

\section{Identification and development of prevention strategies}

Across health and social service sectors, public health departments are responsible for identifying or developing primary prevention interventions or programs to address core public health issues at a population health level. The challenge is that each specific category of child maltreatment is associated with unique but sometimes overlapping risk indicators that require abuse-specific interventions. In a recent review of child maltreatment interventions, only one parenting program was identified as effective at preventing the recurrence of physical abuse and no interventions were identified as preventing the recurrence of neglect; ${ }^{11}$ a small number of interventions resulted in improved behavioural or mental health outcomes in children who had been neglected, exposed to intimate partner violence or sexually abused. ${ }^{11}$ A systematic review of parenting interventions identified complex, multifaceted home visitation programs targeting at-risk families as effective at preventing unintentional injuries in children, a proxy measure of neglect. ${ }^{17}$ Two recent integrative reviews identified the Nurse-Family Partnership (NFP) program as the best available means of preventing child maltreatment; ${ }^{11,18}$ nurses frequently visit targeted young, low-income, firsttime mothers from pregnancy (less than 29 weeks gestation) until the child is 2 years of age. Three randomized controlled trials (RCT) have demonstrated multiple consistent and enduring beneficial maternal and child health outcomes. ${ }^{19-21}$ Further, the NFP program results in significant cost savings; the economic benefits are most likely due to the ability of the program to increase high school graduation rates and help mothers find employment, while also reducing rates of child physical abuse and neglect, substance abuse, crime and use of social welfare. ${ }^{22}$ The NFP is consistently identified as having higher benefit-to-cost ratios per participant than most other prevention programs for parents of infants and young children in the United States. ${ }^{22-24}$

If there are no rigorously evaluated effective interventions, public health researchers can build upon identified risk and protective factors and established theoretical models to develop and test primary prevention interventions. Mrazek and Haggerty ${ }^{25}$ developed a comprehensive framework that many consider the "gold standard" for guiding the development of such interventions. This framework complements the steps of the public health approach and includes five fundamental stages: 1) problem identification and measurement; 2) identification of risk and protective factors and theoretical models from multiple fields; 3 ) intervention development, training of interveners and conduct of small-scale pilot or feasibility studies leading to an RCT that replicates the intervention; 4) conduct of large-scale RCT to establish effectiveness; and 5) broad implementation of the intervention and ongoing program evaluation.

\section{Implementation and evaluation of evidence- based interventions and policies}

There is a pressing need, especially when resources are limited, for all public health departments to implement effective interventions for at-risk families, rather than providing programs that have not been proved adequate or sufficient. The NFP program is internationally recognized as the intervention most capable of preventing child maltreatment. ${ }^{11}$ Widely implemented across the United States, this innovative program is currently being evaluated and replicated in England, Scotland, Germany, the Netherlands and Australia. ${ }^{26}$ The NFP program is an example of a primary prevention intervention that falls within the scope of public health nurse practice; given the provincial/territorial responsibilities for coordinating and funding direct health services, it would be suitable for delivery by a regional public health agency.

Currently, all provinces and territories (with the exception of Nunavut) have implemented home visitation programs, some with a universal postpartum component and all targeting parents and households characterized by risk indicators associated with poor child health and development outcomes. ${ }^{27}$ These programs are primarily offered through or in collaboration with community public health agencies. The home visitation programs have similar goals - to promote healthy child growth and development by increasing parenting capacity through education, community referrals and social supportthough not all are created equal and they vary considerably around program objectives, qualifications of the home visitor (professional, paraprofessional or layperson), intensity and frequency of visits, use of a structured curriculum, timing of enrollment (pregnancy or postpartum) and length of program. To date, no peer-reviewed data are available from provincial/territorial evaluations to estimate the impact of these home-visiting strategies on maternal-child health outcomes. Further, most evaluations have not been conducted using designs that included comparisons of treatment and control groups, ${ }^{27}$ with the exception of Manitoba's Families First program. ${ }^{28}$ Without the use of such rigorous study designs, it is difficult to conclude that home visitation interventions cause any observed changes.

Within the paradigm of evidence-based health care and in the public health sector where resources are often scarce, local public health departments are ethically responsible for implementing those interventions that have been evaluated to significantly affect key maternal-child outcomes, including preventing abuse and neglect. However, since a program may not necessarily demonstrate the same magnitude of positive outcomes in the applied environment as in research contexts, implementation must be preceded by a pilot study and an evaluation using an RCT. ${ }^{16,25}$ This approach is being used to test the feasibility and acceptability of the NFP program within Canadian health and social 
care systems. In 2008, the City of Hamilton Public Health Services and a multidisciplinary team of researchers from McMaster University adapted the NFP curriculum materials for use with young, low-income, first-time mothers living in Hamilton, Ontario. They are conducting a pilot study to test procedures for recruitment; strategies for retention and the feasibility of and methods for collecting child maltreatment data from local child welfare agencies, hospital visit data for mothers and children, and clinical and interview data from participants. Additionally, they are undertaking a qualitative study to explore the acceptability of this targeted intervention to clients and their families, to the Public Health Nurses conducting the home visits and to community professionals involved in referring and providing auxiliary health and social services to clients. Only if the results of these pilot studies are favourable will an RCT be undertaken to measure the impact and cost-benefit of the program in Ontario and other potential communities across Canada.

\section{Conclusion}

As part of a multisectoral response to child maltreatment, the field of public health-building on its strong foundation-is providing leadership and measuring the magnitude and scope of the issue; identifying individual, family and community-level risk indicators for maltreatment; and identifying, implementing and evaluating primary prevention strategies. The next priorities should be to: 1) disseminate the CIS surveillance findings in a timely fashion to those decision makers who are responsible for implementing child and youth injury prevention programs or parenting programs at the provincial/ territorial level; 2) engage public health researchers to conduct secondary analyses of the CIS dataset to answer relevant questions; and 3) establish a process for evaluating the CIS.

The refinement and subsequent dissemination of the CIS surveillance data to public health decision makers will increase their awareness of risk indicators associated with child maltreatment; these risk indicators can then be addressed by prioritizing the implementation of interventions. There is a significant body of literature that identifies the NFP program as the most cost-effective approach to preventing child maltreatment as well as to improving other important maternal-child outcomes. After appropriate evaluation, public health departments could implement the NFP program to enhance the current universal parenting programs.

With the emergence of prevention programs that are known to be effective, public health researchers and decision makers need to continue to advocate for collaborations and resources that facilitate rigorous evaluations of programs. As with any other health care intervention, we should be able to clearly articulate to clients the benefits and potential harms they may experience as a result of consenting to participate in any public health program.

\section{Acknowledgments}

Dr. Jack received support for the preparation of this commentary from the Injury and Child Maltreatment Surveillance Section, Public Health Agency of Canada. She also

TABLE 1

Sector responses to child maltreatment responses to child maltreatment

\begin{tabular}{|c|c|}
\hline Sector & General response to child maltreatment \\
\hline 1. Child Welfare & $\begin{array}{l}\text { - } \quad \text { Respond and investigate reports of observed or suspected maltreatment } \\
\text { - } \quad \text { Offer counselling and other services for perpetrators, children at-risk and maltreated children } \\
\text { - } \quad \text { Provide care for children in out-of-home placements } \\
\text { - } \quad \text { Prevent the recurrence of child maltreatment (secondary prevention) }\end{array}$ \\
\hline 2. Justice & $\begin{array}{ll}\text { - } & \text { Legal reform } \\
\text { - } & \text { Prosecution of perpetrators } \\
\text { - } & \text { Protection of child witnesses }\end{array}$ \\
\hline 3. Education & - Teach students and parents about recognizing, preventing and responding to different types of maltreatment \\
\hline 4. Primary and acute care health services & $\begin{array}{l}\text { - } \quad \text { Identification and documentation of signs and symptoms of maltreatment } \\
\text { - } \quad \text { Assess children exposed to maltreatment } \\
\text { - }\end{array}$ \\
\hline 5. Law enforcement & $\begin{array}{l}\text { - } \quad \text { Respond and investigate reports of suspected or observed maltreatment Determine criminal law violations } \\
\text { - } \quad \text { Identify and apprehend alleged perpetrators } \\
\text { - } \quad \text { File, if necessary, appropriate criminal charges }\end{array}$ \\
\hline 6. Public health & $\begin{array}{l}\text { - Coordinate surveillance systems, including the collection, analysis and dissemination of findings } \\
\text { - Identify, implement and evaluate primary prevention programs }\end{array}$ \\
\hline
\end{tabular}


holds the Institute of Human Development, Child and Youth Health, Reproduction and Child Health New Investigator Personnel Award from the Canadian Institutes of Health Research. Thank you to Lil Tonmyr and Wendy Hovdestad, Injury and Child Maltreatment Section, Health Surveillance and Epidemiology Division, Public Health Agency of Canada, for their feedback on drafts of this manuscript.

\section{References}

1. Leeb RT, Paulozzi LJ, Melanson C, Simon TR, Arias I. Child maltreatment surveillance: uniform definitions for public health and recommended data elements. Atlanta (GA): Centers for Disease Control and Prevention, National Center for Injury Prevention and Control; 2008 Jan.

2. Cicchetti D, Toth SS. Child maltreatment. Annu Rev Clin Psychol. 2005;1:409-38.

3. MacMillan HL, Munn C. The sequelae of child maltreatment. Curr Opin Psychiatr. 2001;14(4):325-31.

4. MacMillan HL, Fleming JE, Trocme N, Boyle MH, Wong M, Racine YA, Beardslee WR, Offord DR. Prevalence of child physical and sexual abuse in the community: results from the Ontario Health Supplement. JAMA. 1997;278(2):131-5.

5. Guyer B. Problem-solving in public health. In: Armenian HK, Shapiro S, editors. Epidemiology and health services. New York: Oxford University Press; 1998. p. 15-26.

6. Hammond WR. Public health and child maltreatment prevention: the role of the Centers for Disease Control and Prevention. Child Maltreat. 2003; 8(2):81-3.

7. Krug EG, Dahlberg LL, Mercy JA, Zwi $A B$, Lozano $R$, editors. World report on violence and health. Geneva $(\mathrm{CH})$ : World Health Organization; 2002.

8. Trocmé N, Fallon B, MacLaurin B, Daciuk J, Felstiner C, Black T, Tonmyr L, Blackstock C, Barter K, Turcotte D, Cloutier R. Canadian incidence study of reported child abuse and neglect-2003: Major findings.
Ottawa (ON): Ministry of Public Works and Government Services Canada; 2005.

9. Pless B. Surveillance alone is not the answer. Inj Prev. 2008;14(4):220-2.

10. Jack S, Tonmyr L. Knowledge transfer and exchange: disseminating Canadian child maltreatment surveillance findings to decision makers. Child Ind Res. 2008;1(1):51-64.

11. MacMillan HL, Wathen CN, Barlow J, Fergusson DM, Leventhal JM, Taussig HN. Interventions to prevent child maltreatment and associated impairment. Lancet. 2009;373(9659):250-66.

12. Thacker SB, Stroup DF. Public health surveillance and health services research. In: Armenian HK, Shapiro S, editors. Epidemiology and health services. New York: Oxford University Press; 1998. p. 61-82.

13. Whitaker DJ, Lutzker JR, Shelley GA. Child maltreatment prevention priorities at the Centers for Disease Control and Prevention. Child Maltreat. 2005;10(3):245-59.

14. Sedlak AJ, Broadhurst DD. Executive summary of the third national incidence study of child abuse and neglect. Washington (DC): US Department of Health and Human Services, Administration for Children and Families, Administration on Children, Youth and Families, National Center on Child Abuse and Neglect;1996.

15. Fluke J, Tonmyr L, Gray J, Bianchi D, Halifax J, Kim C. The ISPCAN working group on Data Collection. Frameworks for international comparison of child maltreatment data. In: World Perspectives on Child Abuse, 8th ed. Daro D, editor. West Chicago (IL): International Society for Prevention of Child Abuse and Neglect; 2008. p. 48-66.

16. Gonzalez A, MacMillan H. Preventing child maltreatment: an evidence-based update. J Postgrad Med. 2008;54(4):280-6.

17. Kendrick D, Barlow J, Hampshire A, Polnay L, Stewart-Brown S. Parenting interventions for the prevention of unintentional injuries in childhood. Cochrane Database of Systematic Reviews. 2007, 4. Art. No.: CD006020. DOI: 10.1002/14651858. CD006020.pub2

18. Gomby DS. Home visitation in 2005: outcomes for children and parents. Washington (DC): Committee for Economic Development, Invest in Kids Working Group; 2005 Jul 18.

19. Kitzman H, Olds DL, Henderson CR Jr, Hanks C, Cole R, Tatelbaum R, McConnochie KM, Sidora K, Luckey DW, Shaver D, Engelhardt K, James D, Barnard K. Effect of prenatal and infancy home visitation by nurses on pregnancy outcomes, childhood injuries, and repeated childbearing. A randomized controlled trial. JAMA. 1997;278(8):644-52.

20. Olds DL, et al. Home visiting by paraprofessionals and by nurses: a randomized, controlled trial. Pediatrics. 2002;110(3):486-96.

21. Olds DL et al. Long-term effects of home visitation on maternal life course and child abuse and neglect. Fifteen-year follow-up of a randomized trial. JAMA. 1997;278(8);637-43.

22. Jones D, Bumbarger BK, Greenberg M, Greenwood P, Kyler S. The economic return of PCCD's investment in researchbased programs: a cost-benefit assessment of delinquency prevention in Pennsylvania [Internet]. Pennsylvania State University (PA): Prevention Research Center for the Promotion of Human Development; 2008 Mar [cited on 2009 mar 1]. Available from: http://prevention.psu.edu/pubs/docs/ PCCD_Report2.pdf

23. Lee S, Aos S, Miller M. Evidence-based programs to prevent children from entering and remaining in the child welfare system: benefits and costs for Washington [Internet]. Olympia (WA): Washington State Institute for Public Policy; 2008 Jul [cited 2009 Mar 1]. Available from: http:// www.wsipp.wa.gov/rptfiles/08-07-3901.pdf 
24. McGroder SM, Hyra A. Developmental and economic effects of parenting programs for expectant parents and parents of preschool-age children [Internet]. Washington (DC): Partnership for America's Economic Success; 2009 Feb 18 [cited 2009 Mar 1]. Available from: http://www.partnershipforsuccess.org/docs/researchproject_

mcgroder_200903_paper.pdf

25. Mrazek PJ, Haggerty RJ, editors. Reducing risks for mental disorders: Frontiers for preventive intervention research. Washington (DC): National Academy Press; 1994.

26. Prevention Research Center for Family and Child Health. Nurse-Family Partnership international program. [Internet]. Denver (CO): University of Colorado Department of Pediatrics; n.d. [cited on 2010 Aug 18]. Available from http://www.ucdenver.edu/ ACADEMICS/COLLEGES/MEDICAL SCHOOL/DEPARTMENTS/PEDIATRICS/ RESEARCH/PROGRAMS/PRC/RESEARCH/

INTERNATIONAL/Pages/international.aspx

27. Petitclerc A. An overview of home-visiting services across Canada. Early Childhood Learning Knowledge Centre Bulletin. 2008 March;3(1):5-8.

28. Healthy Child Manitoba. Families First program evaluation: evaluating the effectiveness of the Families First home visiting program in improving the well-being of at-risk families with preschool children. Winnipeg (MA): Healthy Child Manitoba; 2010 [cited 2010 July 5]. Available from: www.gov.mb.ca/healthychild/families-

first/evaluation.html 